\title{
Most critically ill patients are perceived to die in comfort during withdrawal of life support: a Canadian multicentre study
}

\section{[Les grands malades meurent sans souffrance pendant le retrait du maintien des} fonctions vitales : une étude canadienne]

Graeme M. Rocker DM MHSc FRCPC, ${ }^{*}$ Daren K. Heyland MD MSc FRCPC, $†$ Deborah J. Cook MD MSc FRCPC, Peter M. Dodek MD MHSc FRCPC, $\$$ Demetrios J. Kutsogiannis MD MHS FRCPC, $\mathbb{I}$

Christopher J. O'Callaghan DVM MSC PHD MRCVS

Purpose: Most deaths in intensive care units (ICUs) follow a withdrawal of life support (LS). Evaluation of this process including the related perspectives of grieving family members is integral to improvement of palliation in the ICU.

Methods: A prospective, multicentre, cohort study in six Canadian university-affiliated ICUs included 206 ICU patients (length of stay $\geq 48 \mathrm{hr}$ ) who received mechanical ventilation (MV) before LS withdrawal. We recorded modes, sequence and time course of LS withdrawal and drug usage (4 hr before; 4-8 hr and 8- $12 \mathrm{hr}$ before death). We asked a specified family member to assess patient comfort and key aspects of end-of life care.

Results: MV was withdrawn from 155/206 (75.2\%) patients; 97/I55 (62.6\%) died after extubation and 58/I55 (37.4\%) died with an airway in place. The most frequently used drugs and the cumulative doses [median (range)] in the four hours before death were: morphine I 19/206, 24 mg, (2-450 mg); midazolam 45/206, 24 mg, (2-380 mg); and lorazepam 35/206, 4 mg, (I-80 mg). These doses did not differ among the three time periods before death. Of 196 responses from family members most indicated that patients were perceived to be either totally $(73,37.2 \%)$, very (48, $24.5 \%)$, or mostly comfortable $(58,29.6 \%)$. Times to death, morphine use and family members' perceptions of comfort were similar for each type of change to MV.
Conclusions: Most patients were perceived by family members to die in comfort during a withdrawal of LS. Perceptions of patient comfort and drug use in the hours before death were not associated with the mode or sequence of withdrawal of LS, or the time to death.

Objectif : La plupart des décès qui surviennent dans les unités de soins intensifs (USI) suivent le retrait du maintien de la survie (MS). L'évaluation de cette situation, y compris les perspectives reliées à la peine des membres de la famille, est indispensable pour améliorer les soins palliatifs à I'USI.

Méthode : Une étude de cohorte prospective multicentrique de six USI canadiennes d'affiliation universitaire comportait 206 patients de I'USI (séjour de $=48$ h) qui ont reçu une ventilation mécanique (VM) avant le retrait du MS. Nous avons noté les modes de retrait du MS, leur séquence et leur évolution et l'usage de médicaments (4 h avant ; 4-8 h et 8-12 h avant la mort). Nous avons demandé à un membre de la famille en particulier d'évaluer le confort du patient et les aspects clés des soins palliatifs.

Résultats : La VM a été retirée pour 155/206 (75,2\%) patients ; 97/155 (62,6\%) sont décédés après l'extubation et 58/155 (37,4 $\%$ avec une intubation en place. Les médicaments les plus utilisés et les doses cumulatives [médiane (valeurs extrêmes)] des quatre heures

From the Department of Medicine, Queen Elizabeth II Health Sciences Center, * Halifax, Nova Scotia; Department of Medicine, Kingston General Hospital, $\uparrow$ Kingston, Ontario; Departments of Medicine \& Clinical Epidemiology \& Biostatistics, $\ddagger$ McMaster University, Hamilton, Ontario.; Program in Critical Care Medicine and Center for Health Evaluation and Outcome Sciences, St. Paul's Hospital and University of British Columbia, $\$$ Vancouver, British Columbia; Department of Public Health Sciences and Division of Critical Care Medicine, University of Alberta, I Edmonton, Alberta; Department of Community Health and Epidemiology, Queen's University, Kingston, Ontario, Canada.

Address correspondence to: Dr. G.M. Rocker, \#4457, Halifax Infirmary, 1796 Summer Street, Halifax, Nova Scotia B3H 3A7, Canada. Phone: 902-473-6611; E-mail: gmrocker@dal.ca

Dr. Heyland is a Career Scientist with the Ontario Ministry of Health.

Dr. Cook is a Canada Research Chair.

Partial funding provided by the Canadian Intensive Care Foundation and Queen Elizabeth II Health Sciences Center Research Foundation.

Accepted for publication November 27, 2003.

Revision accepted March 24, 2004. 
précédant le décès ont été : la morphine 1/9/206, 24 mg, (2-450 $\mathrm{mg}$; ; le midazolam 45/206, $24 \mathrm{mg}$, (2-380 mg) et le lorazépam 35/206, 4 mg, ( I-80 mg). Ces doses étaient similaires pour les trois périodes de temps avant la mort. Des 196 réponses des membres des familles, la majorité indiquait que les patients semblaient bénéficier d'un confort total (73, 37,2 \%), d'un grand confort (48, 24,5 \%) ou d'un confort raisonnable (58, 29,6\%). Le temps précédant le décès, l'usage de morphine et la perception des membres de la famille sur le confort du patient ont été similaires pour chacun des types de modification apportée à la VM.

Conclusion : La majorité des patients meurent sans souffrance pendant le retrait du MS selon l'évaluation des membres de leur famille. La perception du confort du patient et l'usage de médicaments pendant les heures qui précèdent la mort ne sont pas associés au mode ou à la séquence du retrait du MS ou à la période de temps avant la mort.

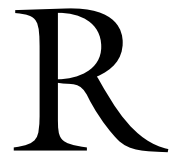

ECENT calls to improve palliation for dying patients in the intensive care unit (ICU) have come from several sources including professional societies, ${ }^{1}$ universities $^{2}$ investigators ${ }^{3,4}$ ethicists $^{5}$ and journal editors. ${ }^{6-9}$ These calls have been made in response to the frequency with which death in the ICU is preceded by withdrawal of life support ${ }^{10-16}$ and due to ongoing concerns, particularly in the United States, about the discomfort of patients dying in hospital. ${ }^{17,18}$

Recent media attention focused on death in the ICU in Canada ${ }^{19,20}$ could be interpreted by the public to imply that the experience for Canadians dying in ICUs is generally poor, despite the lack of empirical Canadian data to support this contention. Research on the process of dying in Canadian ICUs has accrued from prospective observational studies ${ }^{15,21}$ retrospective reviews of medical records, ${ }^{11,14,16}$ surveys of stated practice $^{22}$ and reviews of provincial mortality statistics. ${ }^{23,24}$ Research has also underscored how physician training and experience $e^{21,25,26}$ and type of ICU ${ }^{15}$ influence the frequency, sequence, and tempo with which life support is withdrawn. Reports of family perceptions specifically related to the withdrawal of life support process are few. ${ }^{27-30}$ In a Canadian study, $83 \%$ of 29 respondents indicated that death was compassionate and dignified. ${ }^{30}$

Efforts to provide a 'good death' 31,32 require close attention to the physical, emotional, spiritual and psychological needs of patients and their families. Evaluation of how we currently meet these needs among critically ill patients is a necessary foundation to better palliation in the ICU. Moreover, the per- spectives of grieving family members are important to understand and integrate into our current view of the process of withdrawal of life support.

The primary objective of this multicentre study was to describe the dying process in Canadian ICUs by reporting the mode, sequence, and tempo of withdrawal of life support from critically ill patients and the analgesics and sedatives administered to them. In addition, we sought to determine whether mode or sequence or tempo of life support withdrawal was associated with perceptions of comfort or discomfort reported by family members.

\section{Methods \\ Setting}

As part of a research program of family satisfaction with patient care in the ICU ${ }^{33-35}$ we conducted a multicentre prospective survey involving ICUs in six tertiary care hospitals in five Canadian provinces. The study was conducted in 2000. Participating ICUs varied in size from eight to 24 beds, with bed occupancy ranging between 77 to $98 \%$, and an average nurse to patient ratio of $1: 1$. The majority of participating ICUs had access to a social worker $(5 / 6)$, pastoral care worker $(6 / 6)$ clinical ethicist $(4 / 6)$ and to palliative care $(6 / 6)$. All six ICUs cared for a mixture of medical and surgical patients, functioned as closed units administratively, and were affiliated with medical schools.

\section{Patients and data collection}

A research assistant working in each participating ICU prospectively identified consecutive eligible patients who had been mechanically ventilated during an ICU stay of at least $48 \mathrm{hr}$, and their visiting next of kin. For patients from whom life support was subsequently withdrawn, the research assistant abstracted data after each death. These data included modes of and changes to mechanical ventilation (e.g., a planned reduction or discontinuation of ventilatory support or death despite full mechanical ventilation while other life support modalities such as inotropic agents or dialysis were preferentially withdrawn). In addition, data were collected on changes to oxygen therapy and to the airway (whether patients were extubated or received T-piece ventilation with the endotracheal tube or tracheostomy still in place). By reviewing patient charts, we calculated cumulative drug usage (for opioids and benzodiazepines) for three periods (4 hr before death, 4-8 hr before death and 8-12 hr before death). By collecting data after the patient died, we minimized the influence of the study on endof-life care delivered in participating centres. 
TABLE I Demographic characteristics of 206 patients who died in ICU and who had at least one life support modality withdrawn

\begin{tabular}{ll}
\hline Demographic characteristics & \\
\hline Age mean (SD) & $67.8(14.6)$ \\
*APACHE II score mean (SD) & $25.8(7.4)$ \\
Gender: male $n(\%)$ & $89(43.2)$ \\
Race: caucasian $n$ (\%) & $192(93.2)$ \\
Primary admission diagnostic category $n(\%)$ & $75(36.4)$ \\
$\quad$ Respiratory & $53(25.7)$ \\
$\quad$ Cardiovascular & $25(12.1)$ \\
Sepsis & $20(9.7)$ \\
$\quad$ Gastroenterological & $19(9.2)$ \\
$\quad$ Neurological & $6(2.9)$ \\
$\quad$ Trauma & $8(3.9)$ \\
Other & $7.8(4.2-13.4)$ \\
Median (IQR *) length of stay (days) in ICU & $7.2(3.9-13.8)$ \\
Median (IQR* duration (days) of mechanical & \\
ventilation in 155 patients from whom it was withdrawn
\end{tabular}

*The APACHE II score [the Acute Physiology and Chronic Health Evaluation score (2nd iteration)] is a two component scoring system designed to assess illness severity at intensive care unit (ICU) admission. An APACHE II score of 25 predicts for an ICU population an overall mortality prediction of $>50 \%$. ${ }^{*} \mathrm{IQR}=$ interquartile range.

\section{Family members}

For each adult patient who had been mechanically ventilated before a planned withdrawal of life support, we identified a family member who had visited the patient at least once during the patient's ICU stay (excluding patients from the study if no family member visited). If more than one family member visited, we approached the one designated on the patient's medical chart as next-of-kin. We excluded next-of-kin who could not comprehend the questionnaire due to language, cognitive, or cultural barriers. Three to four weeks after the death of the patient, a letter expressing condolences signed by the Chief Executive Officer of the hospital (or designate) was mailed to the next-ofkin asking them to complete a questionnaire regarding their perspectives on the care of their family member. Four weeks later, a second questionnaire was sent to those family members who had not yet responded. Approval for this study was obtained from the Research Ethics Board of each hospital, each of which waived the need for informed consent.

\section{The questionnaire}

We developed a questionnaire to measure family satisfaction with care provided in the ICU..$^{33,36}$ The overall questionnaire was based on the Conference Board of Canada's "Measuring up: Patient Satisfaction Survey"

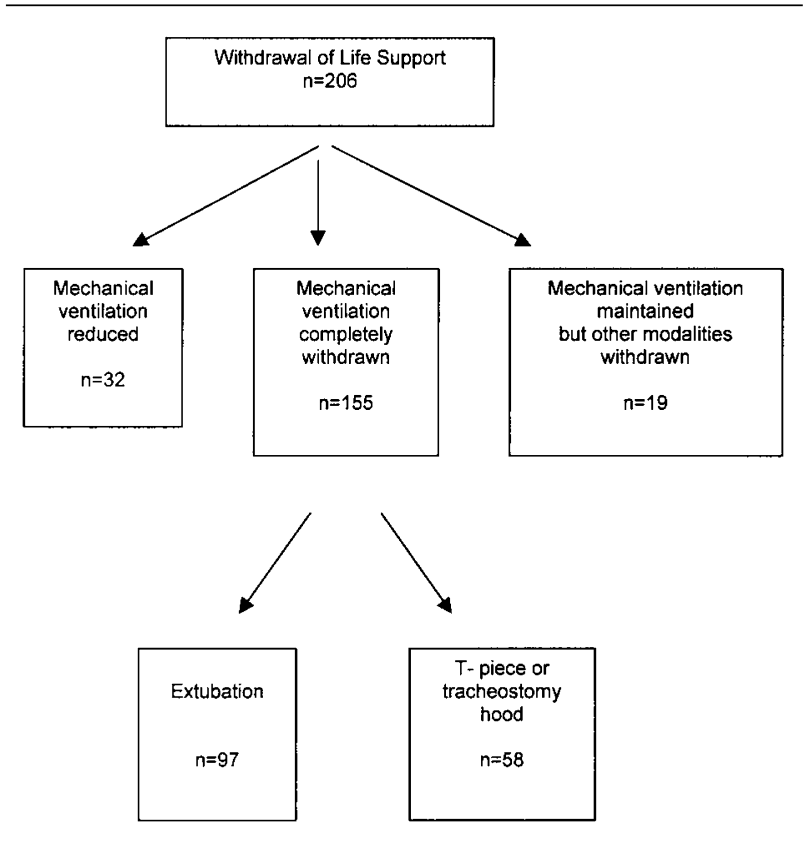

FIGURE Approaches to mechanical ventilation in 206 patients from whom life support was withdrawn.

that we adapted for use in the ICU and pretested for validity and reliability in one of our centres. ${ }^{33,36}$ For the purposes of this study we focused on questions that reflected family perceptions of symptom control and perceptions of the dying process. We include examples of three relevant questions in the Appendix.

\section{Data analysis}

We generated means and standard deviations (or medians and ranges as appropriate), frequency tables, rates, and proportions to describe the patients, their family members, and responses to the survey questions. We developed a stepwise logistic regression model to determine which variables were related to family members' perceptions of patient comfort as patients died. The dependent variable was "totally comfortable" or "very comfortable" vs any lesser degree of comfort; the independent variables included relationship to patient, patient and site characteristics, mode and sequence of withdrawal of life support, and questionnaire responses. When comparing time courses for the process of life support withdrawal and drug use in three time periods we used Fisher's Least Squares Difference for multicomparison testing. 


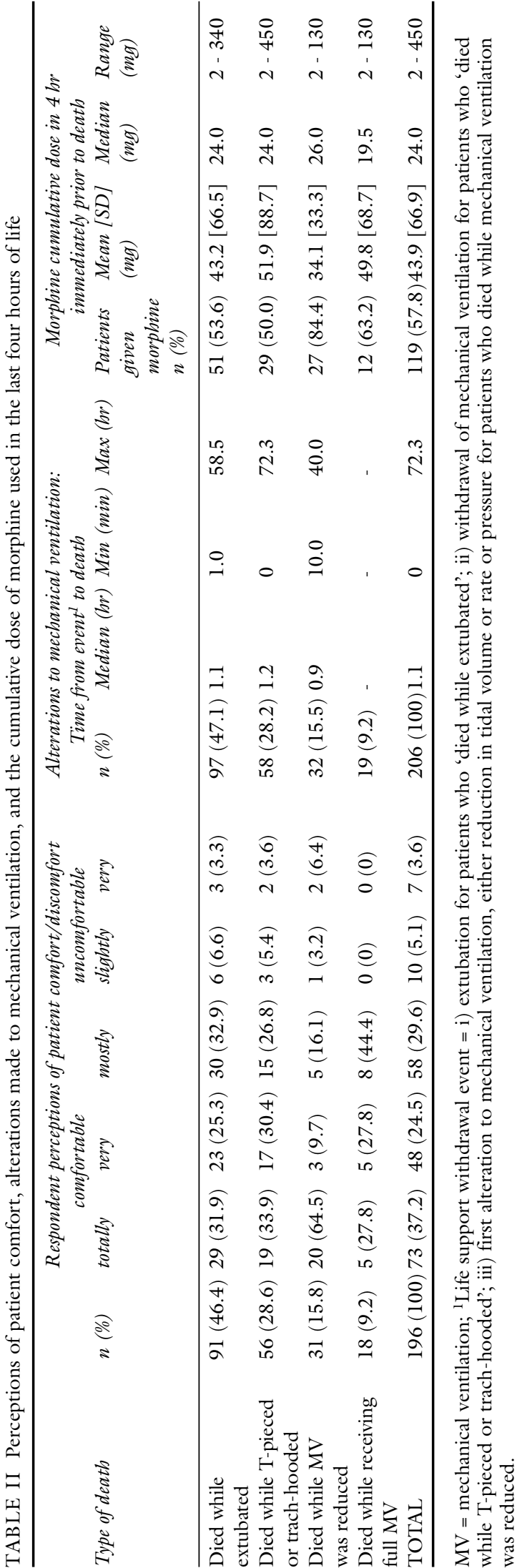

\section{Results}

During the study period, 256 patients who were mechanically ventilated during an ICU stay of at least $48 \mathrm{hr}$ died. Of these, 206 (80.5\%) underwent withdrawal of life support in anticipation of death (Table I). Mechanical ventilation was withdrawn completely from $155 / 206(75.2 \%)$ patients. For the other $51 / 206$ patients, ventilatory support was reduced for $32(15.5 \%)$ patients and $19(9.2 \%)$ died while receiving full mechanical ventilation (Figure). The 155 patients from whom the mechanical ventilator was withdrawn completely were either extubated $(97 / 155,62.6 \%)$ or died with an endotracheal tube or tracheostomy attached to a T-piece apparatus or tracheostomy mask [58/155, (37.4\%), Figure].

In Table II we describe the changes to mechanical ventilation, the times to death associated with each type of change to mechanical ventilation (extubation, T-piece ventilation, reduction in mechanical ventilation), the cumulative dose of morphine used in the last four hours before death, and family members' perceptions of patient comfort/discomfort. Times to death, family members' perceptions of comfort, and usage of morphine were similar for each type of change to mechanical ventilation $(P=0.55, P=0.12$ and $P=0.36$, respectively).

When multiple modalities of life support are in use, they can be withdrawn simultaneously or sequentially. We describe the time course after sequential or simultaneous withdrawals of life support modalities in Table III. There was a trend $(P=0.056)$ towards a shorter intensive care unit length of stay before withdrawal of the first life support modality from patients receiving several rather than fewer life support modalities. The time to death after withdrawal of the first modality did not differ significantly whether single or multiple modalities were withdrawn simultaneously or sequentially $(P=0.51)$.

For the 206 patients who had some form of life support withdrawn, the following drugs were used in the four hours before death: morphine 119/206 (57.8\%); midazolam 45/206 (21.8\%); lorazepam 35/206 (16.9\%). Fewer patients received fentanyl (11/206, $5.3 \%)$, propofol $(7 / 206,3.4 \%)$ or diazepam $6 / 206$, $2.9 \%)$. The cumulative doses in the final four hours before death for these medications [median (range)] were: morphine $24 \mathrm{mg},(2-450 \mathrm{mg})$; midazolam $24 \mathrm{mg}$ (2-380 mg); lorazepam $4 \mathrm{mg}$ (1-80 mg); fentanyl 200 $\mu \mathrm{g}(20-4000 \mu \mathrm{g})$ and propofol $800 \mathrm{mg}(200-1920$ $\mathrm{mg})$. These doses did not differ among the three time periods before death ( $4 \mathrm{hr}$ before; $4-8 \mathrm{hr}$ and $8-12 \mathrm{hr}$ before death, data not shown). The cumulative doses of morphine used in the last four hours of life did not dif- 
TABLE III Timing, mode and consequences of withdrawal of life support

\begin{tabular}{|c|c|c|c|c|}
\hline \multirow{2}{*}{$\begin{array}{l}\text { Number of }{ }^{\star} L S M \\
\text { withdrawn }\end{array}$} & \multicolumn{2}{|c|}{$\begin{array}{l}\text { Days from ICU admission to withdrawal } \\
\text { of first modality Mean (SD) [median] } \\
\text { Mode of withdrawal }\end{array}$} & \multicolumn{2}{|c|}{$\begin{array}{l}\text { Hours to death after withdrawal } \\
\text { of first modality Mean (SD) [median] } \\
\text { Mode of withdrawal }\end{array}$} \\
\hline & Sequential & Simultaneous & Sequential & Simultaneous \\
\hline 1 & $\begin{array}{l}n=32 \\
16.38(19.99) \\
{[8.19]}\end{array}$ & - & $\begin{array}{l}n=32 \\
6.15(12.18) \\
{[1.71]}\end{array}$ & - \\
\hline 2 & $\begin{array}{l}n=27 \\
18.03(28.93) \\
{[9.98]}\end{array}$ & $\begin{array}{l}n=37 \\
9.41(6.56) \\
{[7.71]}\end{array}$ & $\begin{array}{l}n=27 \\
9.85(15.94) \\
{[1.08]}\end{array}$ & $\begin{array}{l}n=37 \\
6.77(10.69) \\
{[1.58]}\end{array}$ \\
\hline 3 & $\begin{array}{l}n=32 \\
9.54(8.21) \\
{[6.83]}\end{array}$ & $\begin{array}{l}n=41 \\
9.87(8.51) \\
{[7.23]}\end{array}$ & $\begin{array}{l}n=32 \\
9.79(15.27) \\
{[0.91]}\end{array}$ & $\begin{array}{l}n=41 \\
6.58(12.67) \\
{[1.03]}\end{array}$ \\
\hline 4 & $\begin{array}{l}n=25 \\
8.63(6.57) \\
{[6.02]}\end{array}$ & $\begin{array}{l}n=9 \\
7.20(4.17) \\
{[5.73]}\end{array}$ & $\begin{array}{l}n=25 \\
5.99(7.57) \\
{[0.56]}\end{array}$ & $\begin{array}{l}n=9 \\
1.23(0.84) \\
{[1.33]}\end{array}$ \\
\hline
\end{tabular}

${ }^{*}$ LSM = Life support modalities: mechanical ventilation; artificial airway; supplemental oxygen and inotropic agents.

TABLE IV Family members' opinions of how well symptoms of agitation, pain and breathlessness were treated in the intensive care unit over the final hours

\begin{tabular}{llllll}
\hline & & Family members' assessment of symptom control in patients $n(\%)$ & \\
& Excellent & Very good & Good & Fair & Poor \\
\hline Agitation & $98(54.44)$ & $56(31.11)$ & $20(11.11)$ & $3(1.67)$ & $3(1.67)$ \\
Pain & $117(59.09)$ & $66(33.33)$ & $13(6.57)$ & $1(0.51)$ & $1(0.51)$ \\
Shortness of breath & $101(54.89)$ & $59(32.07)$ & $14(7.61)$ & $7(3.8)$ & $3(1.63)$ \\
\hline
\end{tabular}

fer according to mode of withdrawal of the mechanical ventilator or artificial airway $(P=0.36$; Table II).

We received responses from 196 family members of whom 195 identified their relationship to the patient. Of these 195 respondents, most were from partners $(43.1 \%)$, children $(33.8 \%)$, and siblings (12.8\%). Most respondents stated that the patients were totally comfortable $(73 / 196,37 \%)$, or very comfortable $(48 / 196,24 \%)$. Fewer respondents stated that the patients were mostly comfortable (58/196, 30\%), slightly uncomfortable $(10 / 196,5 \%)$, or very uncomfortable $(7 / 196,4 \%)$. No patient or respondent characteristic was associated with perceptions of comfort or discomfort. Perceptions of comfort or discomfort did not vary significantly across sites $(P=0.22)$ or ethnic group $(P=0.71)$ or with modes of withdrawal of mechanical ventilation $(P=0.12$; Table II). Symptom control was rated as excellent, very good or good by $96.7 \%, 99 \%$, and $94.6 \%$ of family members for management of agitation, pain and breathlessness respectively (Table IV).

In response to questions enquiring whether life had been prolonged or shortened unnecessarily, 163 $(83.6 \%)$ of respondents stated that neither applied, 23
(11.8\%) stated life had been prolonged and $9(4.6 \%)$ stated that life had been shortened unnecessarily. The vast majority of respondents $(181,92.3 \%)$ felt "very supported" or "supported" by the health care team, 7 (3.6\%) were neutral, and $8(4 \%)$ of respondents reported that they had been abandoned in some way.

\section{Discussion}

In this multicentre study of the withdrawal of life support in six Canadian ICUs, we found that the majority of patients were perceived to die in comfort. The mode of life support withdrawal and the sequence and tempo of the subsequent dying process are not related to family members' perceptions of patient comfort or discomfort. In addition, the amount of sedative and analgesic medication administered to patients dying in the ICU was unrelated to the mode and sequence of life support withdrawal.

In our study, the cumulative dose of morphine is consistent with earlier Canadian ${ }^{14-16}$ and international reports. ${ }^{27,37}$ The dose range of specific medications indicates that ICU practitioners in these participating centres were not uncomfortable using high doses of comfort medication when necessary. Nevertheless, our 
finding that $4 \%$ of family members believed that their loved one was very uncomfortable is an indication that we need to continue efforts to improve symptom control for all dying patients. Similarly, we must address the needs of families who tell us they feel abandoned. However, our results overall compare favourably with limited previous reports of family perceptions of end of life care in the ICU, ${ }^{17,18,28}$ and we were encouraged that $92 \%$ of respondents felt supported by the health care team.

Strengths of our study include the analysis of a large database accrued from six centres in five provinces across Canada, which increases the generalizability of our findings to similar settings. However, our data may not apply to open ICUs or community settings. We received survey responses from 196/206 (95\%) family members participating in this study. We interpret this as a willingness of the public to provide feedback on care of the dying critically ill patient. When seeking to improve end of life care in the ICU, knowing what actually happens is fundamental. By providing empirical data from 206 patients from whom life support was withdrawn and by describing how this process was perceived by family members, we add these family perspectives to extend findings in prior provincial Canadian studies, ${ }^{14-16}$ other single ${ }^{10}$ and multicentre ${ }^{12}$ studies in the United States, and reports of international surveys $^{22,38,39}$ where family perspectives were lacking. This study also builds on our own research program into family satisfaction with ICU care $^{33-35}$ by relating the mode, sequence, and tempo of withdrawal of life support to family perspectives.

Our study has several limitations. First there is no widely available, validated objective measure of true patient comfort or discomfort at the end of life, requiring us to rely on perceptions of comfort and discomfort by family members. Second, we did not interview family members. Interpretation of their narratives using qualitative methodology would provide additional insights into reasons for their responses to our questions. Third, we did not investigate the determinants of satisfaction specifically with how the patient died. We found that few dying critically ill patients were perceived to experience discomfort. However, this study may be under-powered to detect differences in discomfort associated with different approaches to life support withdrawal (i.e., such a difference in discomfort may exist according to the approach to life support withdrawal, but there were too few cases of perceived discomfort to identify such a relationship). Fourth, we cannot discount the possibility that ICU physicians who were aware that the study was ongoing may have been influenced in their end of life care in some way. However, clinicians were unaware that end of life practices and processes were being recorded, although they were aware that a family satisfaction questionnaire was being administered. Families were unaware that the study was taking place until they received a questionnaire after death; thus, their responses would not be influenced by the Hawthorne effect.

Professional opinion and media attention ${ }^{19,20}$ concerning death in the ICU should be informed by rigorously conducted multicentre studies. We were reassured that nearly all dying patients were perceived by their family members to die in comfort, regardless of the approach to withdrawal of life support in the participating ICUs. Nevertheless our research programs will continue to seek ways to improve palliation for all of our dying critically ill patients in Canada.

\section{Acknowledgements}

The Canadian Intensive Care Foundation and Queen Elizabeth II Health Sciences Center Research Foundation provided partial financial support for this study. We acknowledge the contributions of Dr. Joan Tranmer and the Kingston General Hospital ICU Research Working Group who provided valuable comments in the development of this questionnaire. We are grateful to Dr. Sharon Peters (Critical Care Program, Health Corporation of St John's, Newfoundland) and to the research nurses at all six sites who collected the data for this study.

\section{References}

1 Truog RD, Cist AF, Brackett SE, et al. Recommendations for end-of-life care in the intensive care unit: The Ethics Committee of the Society of Critical Care Medicine. Crit Care Med 2001; 29: 2332-48.

2 www.promotingexcellence.org. University of Montana Program Promoting Palliative Care Excellence in Intensive Care.

3 Danis M, Federman D, Fins JJ, et al. Incorporating palliative care into critical care education: principles, challenges, and opportunities. Crit Care Med 1999; 27: 2005-13.

4 Nelson JE, Danis M. End-of-life care in the intensive care unit: where are we now? Crit Care Med 2001; 29(Suppl.): N2-9.

5 von Gunten CF, Ferris FD, Emanuel LL. Ensuring competency in end-of-life care. Communication and relational skills. JAMA 2000; 284: 3051-7.

6 Roy DJ. The times and places of palliative care (Editorial). J Palliat Care 2000; 16 Suppl: S3-4.

7 Rocker GM, Shemie SD, Lacroix J. End-of-life issues in 
the ICU: a need for acute palliative care? (Editorial). J Palliat Care 2000; 16 Suppl: S5-6.

8 Faber-Langendoen K, Lanken PN. Dying patients in the intensive care unit: forgoing treatment, maintaining care. Ann Intern Med 2000; 133: 886-93.

9 Winker MA, Flanagin A. Caring for patients at the end of life. Call for papers (Editorial). JAMA 1999; 282: 1965.

10 Faber-Langendoen K, Bartels DM. Process of forgoing life-sustaining treatment in a university hospital: an empirical study. Crit Care Med 1992; 20: 570-7.

11 Wood GG, Martin E. Withholding and withdrawing life-sustaining therapy in a Canadian intensive care unit. Can J Anaesth 1995; 42: 186-91.

12 Faber-Langendoen $K$. A multi-institutional study of care given to patients dying in hospitals. Ethical and practice implications. Arch Intern Med 1996; 156: 2130-6.

13 Prendergast TJ, Luce JM. Increasing incidence of withholding and withdrawal of life support from the critically ill. Am J Respir Crit Care Med 1997; 155: 15-20.

14 Keenan SP, Busche KD, Chen LM, McCarthy L, Inman $K J$, Sibbald WJ. A retrospective review of a large cohort of patients undergoing the process of withholding or withdrawal of life support. Crit Care Med 1997; 25: 1324-31.

15 Keenan SP, Busche KD, Chen LM, Esmail R, Inman KJ, Sibbald WJ. Withdrawal and withholding of life support in the intensive care unit: a comparison of teaching and community hospitals. The Southwestern Ontario Critical Care Research Network. Crit Care Med 1998; 26: 245-51.

16 Hall RI, Rocker GM. End-of-life care in the ICU. Treatments provided when life support was or was not withdrawn. Chest 2000; 118: 1424-30.

17 Anonymous. A controlled trial to improve care for seriously ill hospitalized patients. The study to understand prognoses and preferences for outcomes and risks of treatments (SUPPORT). The SUPPORT Principal Investigators. JAMA 1995; 274: 1591-8.

18 Hanson LC, Danis M, Garrett J. What is wrong with end-of-life care? Opinions of bereaved family members. J Am Geriatr Soc 1997; 45: 1339-44.

$19 \mathrm{Lu} \mathrm{V}$. Doctors draft rules for end of life care. Toronto Star 2002 September 16, 2002: A.18.

20 Bueckert D. Doctors should provide 'healthy' pain relief even if it hastens death:study. The Canadian Press, National News 2002 September 15.

21 Cook DJ, Giacomini M, Johnson N, Willms D. Life support in the intensive care unit: a qualitative investigation of technological purposes. Canadian Critical Care Trials Group. CMAJ 1999; 161: 1109-13.

22 Cook DJ, Guyatt GH, Jaeschke R, et al. Determinants in
Canadian health care workers of the decision to withdraw life support from the critically ill. Canadian Critical Care Trials Group. JAMA 1995; 273: 703-8.

23 Heyland DK, Lavery JV, Tranmer JE, Shortt SE, Taylor SJ. Dying in Canada: is it an institutionalized, technologically supported experience? J Palliat Care 2000; 16 Suppl: S10-6.

24 Heyland DK, Lavery JV, Tranmer JE, Shortt SE. The final days: an analysis of the dying experience in Ontario. Annals RCPSC 2000; 33: 356-61.

25 Hanson LC, Danis M, Garrett JM, Mutran E. Who decides? Physicians' willingness to use life-sustaining treatment. Arch Intern Med 1996; 156: 785-9.

26 Asch DA, Faber-Langendoen K, Shea JA, Christakis $N A$. The sequence of withdrawing life-sustaining treatment from patients. Am J Med 1999; 107: 153-6.

27 Mayer SA, Kossoff SB. Withdrawal of life support in the neurological intensive care unit. Neurology 1999; 52 : 1602-9.

28 Abbott KH, Sago JG, Breen CM, Abernethy AP, Tulsky $J A$. Families looking back: one year after discussion of withdrawal or withholding of life-sustaining support. Crit Care Med 2001; 29: 197-201.

29 Breen CM, Abernethy AP, Abbott KH, Tulsky JA. Conflict associated with decisions to limit life-sustaining treatment in intensive care units. J Gen Intern Med 2001; 16: 283-9.

30 Keenan SP, Mawdsley C, Plotkin D, Webster GK, Priestap F. Withdrawal of life support: how the family feels, and why. J Palliat Care 2000; 16 Suppl: S40-4.

31 Smith R. A good death. An important aim for health services and for us all. BMJ 2000; 320: 129-30.

32 Emanuel EJ, Emanuel LL. The promise of a good death. Lancet 1998; 351(suppl II): 21-9.

33 Heyland DK, Rocker GM, Dodek PM, et al. Family satisfaction with care in the intensive care unit: results of a multiple center study. Crit Care Med 2002; 30: 1413-8.

34 Heyland DK, Cook DJ, Rocker GM, et al. Decisionmaking in the ICU: perspectives of the substitute decision-maker. Intensive Care Med 2003; 29: 75-82.

35 Heyland DK, Rocker GM, O'Callaghan CJ, Dodek PM, Cook DJ. Dying in the ICU. Perspectives of family members. Chest 2003; 124: 392-7.

36 Heyland DK, Tranmer JE. Measuring family satisfaction with care in the intensive care unit: the development of a questionnaire and preliminary results. J Crit Care 2001; 16: 142-9.

37 Wilson WC, Smedira NG, Fink C, McDowell JA, Luce $J M$. Ordering and administration of sedatives and analgesics during the withholding and withdrawal of life support from critically ill patients. JAMA 1992; 267 : 949-53. 
38 Faber-Langendoen $K$. The clinical management of dying patients receiving mechanical ventilation. A survey of physician practice. Chest 1994; 106: 880-8.

39 Vincent JL. Forgoing life support in western European intensive care units: the results of an ethical questionnaire. Crit Care Med 1999; 27: 1626-33.

\section{APPENDIX}

Examples of three questions we posed to respondents concerning their family member and the order in which we structured the question

Which of the following best describes your views about your family members' life?

During the final hours of your family member's life, which of the following best describes your views?

During the last few hours before your family member's death, which of the following best describes your views?
Their life was:

Prolonged unnecessarily Slightly prolonged unnecessarily Neither prolonged nor shortened unnecessarily Slightly shortened unnecessarily Shortened unnecessarily

I felt they were:

Very uncomfortable Slightly uncomfortable Mostly comfortable Very comfortable

Totally comfortable

I felt:

Very abandoned by the health care team Abandoned by the health care team

Neither abandoned nor supported by the health care team

Supported by the health care team

Very supported by the health care team 